\title{
Gaming Emotions in Social Interactions
}

\author{
EDUARDO B. ANDRADE \\ TECK-HUA HO*
}

\begin{abstract}
One's own emotions may influence someone else's behavior in a social interaction. If one believes this, she or he has an incentive to game emotions-to strategically modify the expression of a current emotional state-in an attempt to influence her or his counterpart. In a series of three experiments, this article investigates the extent to which people (1) misrepresent a current emotional state, (2) willfully acknowledge their strategic actions, (3) choose to game emotions over nonemotional information, and (4) improve their financial well-being from emotion gaming.
\end{abstract}

$\mathrm{T}$ here is limited literature on social interaction in consumer research, let alone on the moderating role of emotion expression (see Buchan, Croson, and Johnson [2004] for a discussion). This is surprising because social interaction often takes place before, during, and/or after the purchase of a product or service in many consumer contexts. Moreover, it seems plausible that emotional display might play a role when people interact with each other. For example, a waiter smiles when handing over a check to a customer in hope for a good tip. Similarly, a car buyer may inflate her anger when negotiating with a car dealer in order to obtain a lower price. Finally, a professional poker player hides his emotions-positive or negative-during a game so as not to reveal his hands. These examples suggest $(a)$ that emotion expression and social interaction may be inherently linked and $(b)$ that the former may be strategically used to influence the outcome of the later.

In this article, we posit that consumers are willing to game emotions - to strategically modify the expression of a current emotional state-in an attempt to influence a third party. In a series of three experiments, we investigate the extent to

*Eduardo B. Andrade is assistant professor of marketing (eandrade@ haas.berkeley.edu) and Teck-Hua Ho is the William Halford Jr. Family Professor of Marketing (hoteck@haas.berkeley.edu). Both authors are at Haas School of Business, University of California, Berkeley, 545 Student Services Building, Berkeley, CA 94720-1900. Correspondence about this article should be addressed to Eduardo B. Andrade. The authors thank Bruce Barry, Cameron Anderson, and Joel B. Cohen for their helpful comments on previous versions of this article. They also thank Vincent Chan, Jason Harakh, Esther Hwang, Julia Lee, Caroline Wang, and the Xlab for their assistance with data collection. Taizan Chan designed and developed the software system for running the experiments. The article also benefited from helpful comments from seminar participants at Yale University (SOM) and the Bay Area Marketing Colloquium. Finally, the authors would like to thank the editor, the associate editor, and the three reviewers for their clear guidance and helpful suggestions.

John Deighton served as editor and Baba Shiv served as associate editor for this article.

Electronically published April 10, 2009 which consumers (1) misrepresent a current emotional state, (2) willfully acknowledge their strategic actions, (3) prefer to game emotions over nonemotional information, and (4) improve their financial well-being from emotion gaming.

\section{EMOTIONS IN SOCIAL INTERACTIONS}

Although absent in the consumer behavior literature, research on the impact of emotions on social interactions has received growing attention in social psychology and organizational behavior (Allred 1999; Barry and Oliver 1996; Davidson and Greenhalgh 1999; Morris and Keltner 2000; Thompson, Nadler, and Kim 1999). The earliest tradition has focused on how one's emotions influence one's own behavior in a dyadic relationship. More than 40 years of research have shown that, in general, happy people are more willing to help, to cooperate with, and to trust others in a negotiation (Allred et al. 1997; Baron 1990; Baron et al. 1990; Berkowitz 1987; Carnevale and Isen 1986; Dunn and Schweitzer 2005; Forgas 1998). By contrast, people experiencing negative emotions-particularly, anger-are in general less trustworthy, more competitive, and more selfish (Allred et al. 1997; Berkowitz 1989; Baron 1990; Baron et al. 1990; Dunn and Schweitzer 2005; Pillutla and Murnighan 1996; Sanfey et al. 2003; Travis 1989).

A more recent research stream has asked whether other people's emotions influence one's own decision in negotiations (Andrade and Ho 2007; Kopelman, Rosette, and Thompson 2006; Sinaceur and Tiedens 2006; van Kleef, de Dreu, and Manstead 2004, 2006). Van Kleef et al. (2004) show that proposers frequently revise their offer after knowing receivers' allegedly angry, neutral, or happy reactions to their prior offer (e.g., an angry reaction: "This offer makes me really angry," 61). Proposers concede more to an angry than to a happy receiver, with neutral being somewhere in the middle. These results show that other's integral affect, that is, the angry feeling generated by an unappealing offer during a negotiation, is taken into account in a subsequent 
negotiation. Andrade and Ho (2007) move a step further by showing that people can take other people's feelings into account even when the source of affect is incidental, and as a result, the affective state is independent of the level of satisfaction associated with the negotiation process or outcome. In an ultimatum-type game, where proposers move first by dividing a given pot of cash (keeping $50 \%$ or $75 \%$ of the pot) and receivers respond by choosing the size of the pot (from $\$ 0.00$ to $\$ 1.00$ ), proposers are more likely to make an uneven offer (i.e., to keep $75 \%$ of the pot) if they are told that receivers have watched a funny sitcom rather than a movie clip portraying anger in an unrelated study prior to the game. However, this systematic effect occurs only if proposers know that receivers are not aware of the sharing of their affective state. Also in an ultimatum setting, Kopelman and colleagues (2006) demonstrate that receivers are more likely to accept a given offer from a proposer (confederate) who displays positive (vs. negative or neutral) emotions. Similarly, Sinaceur and Tiedens (2006) show that receivers with unattractive outside options concede more to a purportedly angry (vs. neutral) proposer. Finally, van Kleef et al. (2006) show that people concede more to an opponent who displays disappointment or worry and less to an opponent who displays guilt. In short, there has been growing evidence suggesting that one's emotions influence the other's decision in the negotiation process. If this is the case and people are able to intuit it, they may be willing to strategically modify the expression of a current emotional state in order to improve their well-being in a given social interaction.

\section{GAMING EMOTIONS}

The impression management literature has provided robust evidence that, in a social interaction, people are usually willing to control or modify displayed aspects of the self for strategic reasons (Baumeister 1982; Goffman 1959; Schlenker and Pontari 2000; Vohs, Baumeister, and Ciarocco 2005). Emotions may well be one of such displayed aspects (Jones and Pittman 1982). Since emotions are powerful social cues (Keltner and Kring 1998; Morris and Keltner 2000), people have an incentive to strategically express their feelings (Barry 1999; Thompson et al. 1999). For example, employees are frequently obliged, either by implicit social norms or by explicit company policies, to display, and usually to fake, specific emotional states. Amusement parks (Rafaeli and Sutton 1987), airline companies (Hochschild 1983), and fast food chains (Boas and Chain 1976) often suggest or mandate that their employees continuously display positive feelings when they interact with their customers.

On the one hand, such dissociation between inner and outer feelings can have negative physiological and psychological costs, which can reduce employees' well-being in the long run (Ashforth 1993; Coté 2005; Gosserand and Diefendorff 2005; Grandey 2003; Hochschild 1983; Morris and Feldman 1996). For instance, there is evidence to suggest that constant pressure to deliberately fake feelings is negatively correlated with job satisfaction (Grandey 2003). Similarly, direct evi- dence has shown that deliberate attempts at suppressing one's positive and negative feelings can also be physiologically costly (Gross and Levenson 1997).

On the other hand, it is possible that people may deliberately choose to game emotions, especially if by doing so they gain significant benefits that can outweigh the associated physiological and psychological costs (Rafaeli and Sutton 1987). It has been shown that customers give a higher tip when positive feelings are made salient in a restaurant, either through a server's "maximal" smile (Tidd and Lockard 1978) or a joke card next to the check (Gueguen 2002). Similarly, receivers are more likely to accept an offer in an ultimatum game when they are matched with a proposer-a confederate-who expressed more positive (vs. negative or neutral) emotions (Kopelman et al. 2006). Consequently, those who intuit that their emotions will influence other people's decisions may wish to game emotions.

A few studies appear to suggest this conjecture. In a consumer survey, Spiro (1983) shows that emotion gaming is one of the persuasion tactics used by spouses to resolve disagreements about a purchase decision. In an experimental setting, Clark, Pataki, and Carver (1996) demonstrate that, when people are presented with a goal to get others to like them, they deliberately report higher levels of happiness relative to their own previous assessment before knowing the goal. The authors argue that, if people intuit that happiness and likeability are positively associated, they may intensify their happiness in order to be perceived as a more likeable person (see also Pataki and Clark 2004). Finally, children are less likely to display either a positive or a negative emotion in the presence of their friends than in front of their parents or when they are alone (Zeman and Garber 1996).

Surprisingly, there is little empirical evidence to simultaneously examine $(a)$ the extent to which individuals willfully modify the expression of a given emotional state during a social interaction in an attempt to increase their financial well-being and $(b)$ whether such a deliberate strategy actually influences the outcome of the interaction. For instance, in a comprehensive review of the affect and negotiation literature, Barry (2008) notes: "It is sufficiently easy to present experimental participants with manipulations of 'tactical' emotion, but not so easy to study how negotiators actually use emotion tactically. In other words, we can explore how individuals respond to emotional gambits with conventional methods [as Kopelman et al. 2006 have], but not necessarily how individuals themselves choose to engage and deploy emotions strategically" (103).

Also, when people game emotions, they are actually making two choices: (1) whether or not to misrepresent a given expression and, if so, (2) whether to misrepresent emotional or nonemotional cues. We posit that, because emotion gaming is readily available and well learned and because it is perceived to be more persuasive, people will, in many circumstances, be more likely to engage in emotion gaming than in the misrepresentation of nonemotional information. In fact, there is evidence supporting the relative persua- 
FIGURE 1

OVERVIEW OF THE EXPERIMENTAL PROCEDURE/DESIGNS

\begin{tabular}{|c|c|c|c|c|c|}
\hline & \multicolumn{3}{|c|}{ Dictator Game } & \multicolumn{2}{|c|}{ Ultimatum Game } \\
\hline & $\begin{array}{c}\text { Emotion } \\
\text { Manipulation }\end{array}$ & $\begin{array}{c}\text { Emotion } \\
\text { Measurement } 1\end{array}$ & Instructions & Emotion Gaming & $\begin{array}{l}\text { Targeted } \\
\text { Social } \\
\text { Interaction }\end{array}$ \\
\hline Experiment 1 & $\begin{array}{l}\text { Unfair Offer } \\
\text { (e.g., } \$ 3.50 \text { out o }\end{array}$ & Anger 1 & & $\begin{array}{l}\text { Anger } 2 \text { (Control) } \\
\text { Anger } 2 \text { (Displayed) }\end{array}$ & $\begin{array}{l}\text { Proposer's } \\
\text { Offer }\end{array}$ \\
\hline
\end{tabular}

Anger 2 (C)/Anger 3 (D)

Experiment $2 \quad$ Unfair Offer Anger 1

Anger 2 (D)*

Proposer's

(e.g., $\$ 3.00$ out of $\$ 10.00)$

*Manipulation - Credibility

of the Information

Offer

Unfair Offer $\quad$ Expectation 1
(e.g., \$3.00 out of \$10.00) Anger 1

Experiment $3 \quad$ (e.g., $\$ 3.00$ out of $\$ 10.00)$ Anger 1

Choice of Self-report 2 Proposer's

Offer

siveness and strength of affect-laden messages (Deighton, Romer, and McQueen 1989; Pham et al. 2001). We suspect that people can intuit the greater effectiveness of emotionladen cues and prefer to game emotions over nonemotional information.

In summary, this article advances the literature by first proposing a simple experimental paradigm that allows us to directly capture people's strategic display of emotions. Second, it assesses whether or not people are willing to acknowledge their emotion gaming behavior. Third, it tests whether emotion gaming actually pays. Finally, it investigates the extent to which people prefer to game an emotional state (i.e., anger) over another piece of information (i.e., expectation).

\section{OVERVIEW OF THE EXPERIMENTS AND GENERAL HYPOTHESES}

Three experiments are conducted with a similar procedure. Participants arrive at the lab and are randomly assigned to one of the laptops located in the east or west side of the room. The instructions inform them that they will be participating in two tasks involving interactive decision making. In addition, they are told specifically that their payment is contingent on the outcome of the two tasks. Thus, participants' decisions are consequential, and they have an incentive to perform well (their potential payoffs can range from $\$ 2.50$ to $\$ 16.50)$. Finally, all experiments are Web based, so that interactions between participants occur $(a)$ anonymously and $(b)$ in real time.

In both tasks, participants play a two-person game (see fig. 1). They are told that they will be playing the same role and will be matched with the same partner in both games. The Dictator Game (DG) is used in task 1, whereas the Ultimatum Game (UG) is used in task 2. In the DG, there are two players (labeled as proposer and receiver). The proposer is endowed with a pot of money and asked to divide the pie between himself/herself and the receiver. The receiver has no choice and must accept the offer as proposed (i.e., the proposer is a dictator). The DG is used to manipulate receivers' level of anger (e.g., proposers are led to make an unfair offer to receivers who must accept it).

In the UG, a proposer is also endowed with a pot of money and asked to propose a division of the pie between himself/herself and the receiver. However, unlike the DG, the receiver in an UG can either accept or reject the proposer's offer. If the receiver rejects an offer, both players earn nothing. Note that the UG is the targeted market ex- 
change between a consumer and a seller. It is meant to capture the common retail setting where a seller (i.e., proposer) posts a fixed price and a consumer (i.e., receiver) must decide whether or not to accept the price offer. The UG can also capture the very last phase of a complex negotiation involving multiple stages (e.g., buying a new car) where one party gives the final take-it-or-leave-it offer before walking away from the negotiation table.

\section{Emotion Gaming}

Right after the DG (i.e., the emotion manipulation), receivers are asked to report how angry they are feeling on a 101-point scale (report 1). After a short duration (filler task), participants are introduced to the UG. Right before proposers decide on the division of the pie, receivers are asked to report once again their current level of anger (report 2). Half of them are informed that their last report of anger will be shown to proposers before proposers make a decision on the offer (displayed emotion condition). The other half is simply told that the researcher wants to assess how emotions change over time (control condition). We hypothesize that receivers will misrepresent their actual level of anger by inflating it (i.e., report $2>$ report 1) when they know that proposers will see their anger display before deciding on their offer (experiments 1,2, and 3). We further hypothesize that receivers will be ready to acknowledge their strategic display of emotions when asked to explain why they decided to report a different level of anger (experiment 2 ) and that receivers will prefer to send an inflated level of anger rather than an inflated level of expectation when given a choice (experiment 3).

\section{Effectiveness of Emotion Gaming}

After being presented (or not) with the matched receivers' level of anger, proposers then determine their division of the pie. We hypothesize that the proposers' offer is positively correlated with the receivers' reported level of anger (experiment 1). That is, angrier receivers will get a higher share of the pie. However, this effect will be contingent on the credibility of the reported anger information. When proposers know that receivers might be gaming emotions, this conceding effect should diminish (experiment 2). Finally, we posit that anger will be perceived as a more persuasive tactic than plain information about one's prior expectation in the UG game. That is, proposers who are informed about receivers' anger - "This previous offer [in the DG] made me angry"- - are more likely to concede than proposers who are informed about receivers' violated expectations- "The previous offer [in the DG] was below my expectations"-(experiment 3). Figure 1 shows the overall design of the three experiments.

\section{Changes in Emotion Expression or Experience?}

It is well established that physical postures, particularly facial expressions, can actually change one's current experienced emotions (for a review, see Adelmann and Zajonc
[1989]). Therefore, when people attempt to display an emotional state, they may end up changing it. To control for this potential confound, receivers in all three experiments are asked to report their experienced emotion on a 101-point scale on a computer screen. Since there are no physical changes required as a function of emotional expression (e.g., smile or frown), this procedure allows us to separate changes in emotion expression (i.e., emotion gaming) from changes in emotion experience.

\section{EXPERIMENT 1}

\section{Method}

Participants and Design. One hundred and fifty-two students from the University of California, Berkeley, participated in this experiment. They were paid a flat $\$ 5.00$ showup fee plus additional cash earnings contingent on the outcome of the games. The experiment adopted a 2 (affective information: control vs. displayed emotion; between) $\times 2$ (self-report of anger: first vs. second; within) mixed design.

Procedure. Participants came to Xlab (a behavioral lab at University of Californina, Berkeley) and were randomly assigned to either the east or the west side of the room. The general instructions informed the participants that the experiment was about interactive decision making and that participants would be presented with two Web-based tasks. Each participant on one side of the room was randomly matched with another person from the other side of the room. Participants were randomly assigned the role of a proposer or a receiver and were told that in both forthcoming tasks they $(a)$ would be playing the same role and $(b)$ would be matched with the same partner. They were informed that they would play the two games in complete anonymity and that their total cash earnings in the experiment would be the sum of their earnings in each of the two games (i.e., earnings in $\mathrm{DG}+\mathrm{UG}$ ) plus the $\$ 5.00$ flat fee.

$D G$. The DG was a variant of the standard dictator game. In the standard dictator game, there are two players (labeled as proposer and receiver). The proposer is endowed with a pot of money and asked to divide the pie between himself/ herself and the receiver. The receiver has no choice but to accept the offer as it is. In our version, the proposer was endowed with $\$ 10.00$ and asked to choose a division of the pie. To systematically manipulate the offers made and, as a result, the receivers' emotional reaction to it, proposers in the DG had only two options to choose from (e.g., "Proposer gets $\$ 7.00$ and Receiver gets $\$ 3.00 "$ or "Proposer gets $\$ 3.00$ and Receiver gets \$7.00”). Proposers were randomly assigned to one of the three possible choice sets (P:\$7.00/ $\mathrm{R}: \$ 3.00$ or $\mathrm{P}: \$ 3.00 / \mathrm{R}: \$ 7.00 ; \mathrm{P}: \$ 6.50 / \mathrm{R}: \$ 3.50$ or $\mathrm{P}: \$ 3.50 / \mathrm{R}$ : $\$ 6.50$; P:\$6.00/R:\$4.00 or P:\$4.00/R:\$6.00). Importantly, receivers were not aware of this choice constraint. In fact, these different choice sets also allowed us to disguise from receivers the constraint the experimenter imposed on proposers (i.e., the word of mouth after the experiment could 
be problematic if all receivers got identical offers in the DG). In all three choice sets, we expected proposers to select the option that provided them with a larger share of the pie.

Measuring Anger. After receiving a fair or unfair offer and being required to accept it, receivers were asked to report their level of anger on a 101-point scale: "Right now, I feel _ $(0=$ not angry at all, $50=$ moderately angry, $100=$ very angry; any number from 0 to 100 is allowed)."

UG. Participants were then introduced to task 2 (UG). They were reminded that they were $(a)$ playing the same role and $(b)$ matched with the same partner. The proposers were once again endowed with $\$ 10.00$ and asked to propose a division of the pie. Unlike the DG, however, receivers could either accept or reject the offer. Any division of the pie was possible, and both proposers and receivers were fully aware of this possibility.

Gaming Anger. Before the targeted social interaction began (i.e., before proposers proposed a division of the pie), receivers were asked to report once again their current level of anger. At this point, a manipulation was introduced. Half of them were informed that, since the game required full information disclosure, this second report would be sent to their matched proposers (displayed emotion condition). The other half were not provided with this additional information (control condition). They were simply told that the experimenter wanted to assess how their emotions changed over time. A short filler task (an irrelevant 27-item survey) was inserted between games in an attempt to mitigate people's level of anger over time. Thus, any inflation of anger would provide initial evidence that receivers were indeed gaming emotions.

In summary, all receivers in the DG were expected to receive an unfair offer, which had to be accepted. Right after, they were asked to report their current level of anger. Following this, a short distracting task took place. Participants were then introduced to the UG. Just before the targeted social interaction (i.e., before proposers proposed a division), receivers were again asked to report their level of anger. Half of the receivers were told that their second report would be seen by their matched proposers (displayed emotion condition), whereas the other half were told that we wanted to assess whether/how their emotions changed over time (control condition). As a result, the respective matched proposers either saw or did not see the second report of anger, and they then made their offer, which was either accepted or rejected by their matched receivers.

\section{Results}

Manipulation Check. As expected, all proposers chose the option that gave them a larger share of the pie. It means that receivers were offered $\$ 4.00, \$ 3.50$, or $\$ 3.00$ out of $\$ 10.00$, depending on the provided choice set. More unfair offers led to higher receivers' level of anger at time 1 $\left(M_{\$ 4.00}=26.4, \mathrm{SE}=4.7\right.$ vs. $M_{\$ 3.50}=45.0, \mathrm{SE}=5.1 \mathrm{vs}$. $M_{\$ 3.00}=41.7, \mathrm{SE}=5.3 ; F(2,73)=4.16, p<.05, \eta_{p}^{2}=$
.10). Most important, the offer size in the DG did not interact with the two main factors in the design $(F(2,70)=1.19$, $\left.p>.10, \eta_{p}^{2}=.03\right)$. In other words, the to-be-reported findings were not constrained to a given range of anger reactions or offer size. The levels of this factor were then collapsed.

Gaming Anger. An analysis of variance with repeated measures was conducted to test the extent to which the timing of the report (first vs. second) and affective information (control vs. displayed) interacted on the self-reported anger. The results confirmed the interaction $\left(F(1,74)=8.2, p=.005, \eta_{p}^{2}=\right.$ .10 ; see fig. 2). To be precise, the control condition showed that the receivers' level of anger in the second report $(M=$ $32.8, \mathrm{SE}=4.6$ ) was marginally lower than in the first report $\left(M=39.1, \quad \mathrm{SE}=4.1 ; \quad F(1,74)=2.94, \quad p<.10, \quad \eta_{p}^{2}=\right.$ $.04)$, probably due to the fact that (a) a time delay/filler task took place between the two reports and $(b)$ receivers were in a less disadvantageous position in the UG relative to the DG. However, when receivers knew that their second report of anger would be sent to their matched proposers (i.e., displayed emotion condition), the second report $(M=43.5, \mathrm{SE}=5.0)$ was significantly higher than the first one $(M=34.4, \mathrm{SE}=4.5$; $\left.F(1,74)=5.3, p<.05, \eta_{p}^{2}=.07\right)$. In other words, receivers pretended to be angrier than they actually were right before the proposers decided on how to divide the pie.

Did the Strategy Work? To test whether or not proposers in the displayed condition considered their matched receivers' level of anger before deciding on how to divide the $\$ 10.00$, we ran a Pearson correlation between the receivers' displayed level of anger and the share of the pie offered to them by their matched proposers. The results show a significantly positive correlation between the two variables $(r=.38, p<.05)$. In other words, purportedly angrier receivers were offered a larger share of the pie from their

FIGURE 2

GAMING ANGER (EXPERIMENT 1)

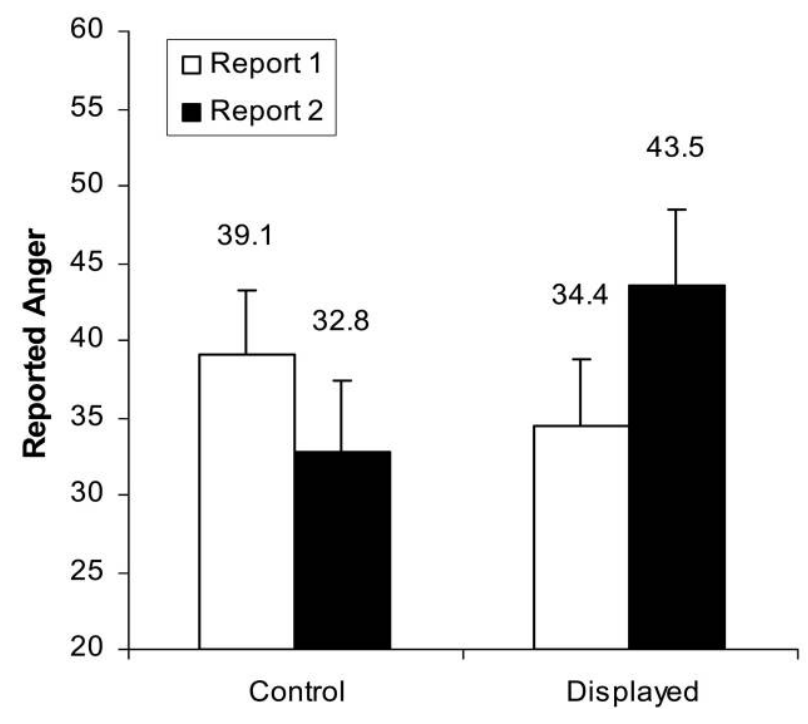


matched proposers. Note that, in the control condition, where there was no display of anger to proposers, the correlation between these two variables was not significant $(r=.09, p>.10)$. The difference between the two correlations was significant at the margin $(z=1.22, p=.10$, one-tailed test).

\section{Discussion}

Experiment 1 provides initial evidence that people game emotions in social interactions. The control condition shows that receivers were actually experiencing a lower level of anger over time. However, when receivers knew that their level of anger would be presented to their matched proposers before the latter proposed a division of the pie, they exaggerated their level of anger in a deliberate attempt to improve their chance of getting a good offer. Also, the receivers' belief about the proposers' reaction to an angry display was accurate. Receivers who reported higher levels of anger ended up extracting a higher share of the pie from their matched proposers.

This experiment, however, has a few caveats and raises some questions. It is possible that the receivers in the displayed emotion condition are not gaming emotion and that the higher level of anger represents their true feeling state. Since, in this condition, the source of anger (i.e., the matched proposer) is made salient right before the second report of anger ("Your current feelings will be sent to the matched proposer") participants might have indeed felt worse during the second report (e.g., "Just thinking of this guy makes me feel angry"). In experiment 2, thought processes after the second report of anger are obtained to assess whether and, if so, why participants deliberately inflate their anger.

Also, one might argue that, even if people are indeed inflating their anger, this might take place only when it is easy to justify the increase without having to acknowledge that one is in fact lying (see Mazar, Amir, and Ariely 2008). For instance, in the current paradigm, participants could have rationalized their higher second report of anger by blaming either their inattention during the first report (e.g., "I was not paying attention to my first report 5 minutes ago. This is my true level of anger.") or the filler task they had just completed (e.g., "The boring filler task between games fueled my anger"). This ease to rationalization might have facilitated their willingness to game emotions. In the second experiment, we also address this potential boundary condition by allowing participants in the control condition to change their mind (i.e., revise or confirm their level of anger) right after the second report. That should make any justification of emotional change much more difficult.

Finally, it is an open question whether proposers respond to receivers' level of anger as long as they see themselves as the source of anger or whether the credibility of the emotion information also plays a major role. In experiment 1 , not only were proposers the source of anger but they also had no reason to believe that receivers might be inflating it. In experiment 2, we test whether uncertainty about the credibility of receivers' reported level of anger leads pro- posers to disregard receivers' reported emotions even when they are the source of receivers' anger.

\section{EXPERIMENT 2}

\section{Method}

Participants and Design. One hundred and eighty-four students from the University of California, Berkeley, participated in this experiment. They were paid a flat $\$ 5.00$ show-up fee plus additional cash earnings contingent on the outcome of the two games. The experiment adopted a 2 (affective information: control vs. displayed emotion; between $) \times 2$ (self-report of anger: first vs. second; within) mixed design. Also, a third report of anger was added to the control condition only. Within the control condition, it was possible to assess whether this third report significantly differed from the second report. Finally, the credibility of receivers' emotion information-to be sent to their matched proposers - was manipulated. Before deciding on the division of the $\$ 10.00$, proposers knew that receivers could (vs. could not) be gaming emotions.

Procedure. The procedure was similar to the one used in experiment 1 except for the following changes. First, a third report of anger was gathered in the control condition. Specifically, right after the second report, receivers were informed that their current level of anger would to be sent to their matched proposers. Therefore, they should either confirm or revise the second report before sending it off. They were further informed that proposers would be exposed to the last (third) report of anger only. The third report allows us to test whether receivers are still willing to inflate their current level of anger in a situation where it may be difficult and even awkward to justify a change to their current affective state unless one is open to acknowledging an emotion gaming strategy. Second, an open-ended question after the last report of anger asked all receivers to indicate whether or not they had changed their reported emotion and why they had entered that particular number on the anger scale. Finally, half of proposers were informed that receivers could potentially be gaming emotions. Specifically, proposers were told that receivers reported their level of anger after knowing that this information would be sent to their matched proposers. The other half of proposers were told that receivers could not have strategically misreported their emotions. In this condition, proposers were informed that receivers reported their level of anger before knowing that this affective information would be sent to their matched proposers. In both cases, the information was provided in the paragraph below the anger message. We assessed the extent to which proposers' reaction to receivers' level of anger would be a function of the credibility of the emotion information.

\section{Results}

Manipulation Check. In the DG, half of the proposers were given the option to choose between P:\$6.00/R:\$4.00 
vs. P:\$4.00/R:\$6.00. The other half was presented with the $\mathrm{P}: \$ 6.50 / \mathrm{R}: \$ 3.50$ vs. P:\$3.50/R:\$6.50 option. All proposers chose the option that gave them a larger share of the pie. This means that receivers were offered $\$ 4.00$ or $\$ 3.50$ out of $\$ 10.00$, depending on the choice set. More unfair offers increased receivers' level of anger at the first report $\left(M_{\$ 4.00}=32.6, \mathrm{SE}=3.8\right.$ vs. $M_{\$ 3.50}=47.6, \mathrm{SE}=3.9$; $\left.F(1,90)=7.34, p<.05, \eta_{p}^{2}=.08\right)$. Importantly, this factor did not interact with the two main factors in the design $\left(F(1,88)=1.22, p>.10, \eta_{p}^{2}=.01\right)$. In other words, similar to experiment 1 , the to-be-reported findings were not constrained to a given range of anger reaction or offer size. The levels of choice set were then collapsed.

Gaming Anger. An analysis of variance with repeated measures was conducted to test the extent to which the time of the self-report of anger (first vs. second) and the emotion information (control vs. displayed) interacted on the level of anger. The results confirmed this interaction $(F(1,90)=13.62$, $\left.p<.001, \eta_{p}^{2}=.13\right)$. In the control condition, receivers' second report of anger $(M=33.1, \mathrm{SE}=4.1)$ was actually lower than the first report $(M=41.3, \mathrm{SE}=4.0 ; F(1,90)=3.95$, $\left.p=.05, \eta_{p}^{2}=.04\right)$. However, when receivers knew that their second report of anger would be sent to their matched proposers (i.e., displayed emotion condition), the second report $(M=$ 51.9, $\mathrm{SE}=4.12$ ) was significantly higher relative to the first one $(M=38.5, \mathrm{SE}=4.1 ; F(1,90)=10.43, p<.01$, $\left.\eta_{p}^{2}=.10\right)$. As in experiment 1 , receivers pretended to be angrier than they actually were right before proposers proposed a division of the pie.

Recall that a third report of anger was introduced in the control condition. After receivers reported their level of anger for the second time, they were told that this information would be sent to proposers. They were then given the opportunity to confirm or revise their current level of anger. The results show that, in this condition, receivers' third report of anger was significantly higher than the second one $\left(M_{2 \text { nd }}=33.1\right.$, $\mathrm{SE}=3.4$ vs. $M_{3 \mathrm{rd}}=50.3, \mathrm{SE}=4.7 ; F(1,45)=20.65$, $p<.001, \eta_{p}^{2}=.31$ ), even though only a few seconds took place between these two measures (see fig. 3).

Thought Processes. Right after the final report of anger (second report in the displayed emotion condition and third report in the control condition), participants were asked to indicate whether or not they had changed the reported emotion relative to the previous measurement and why they had entered the specific number on the anger scale. Two coders, blinded to the purpose of the experiment, classified the thoughts into three categories: $0=$ actual anger, $1=$ strategic display of anger, and $2=$ other. "Actual anger" means that participants' last level of anger represents their true anger. "Strategic display of anger" means that participants acknowledge that they are exaggerating or reducing their emotions in a deliberate attempt to reduce the chances of getting an unfair offer from the matched proposer. The coders agreed on $93.5 \%$ of the assigned categories. Disagreements were solved by consensus.

The results show that, whether it represented participants'
FIGURE 3

GAMING ANGER (EXPERIMENT 2)

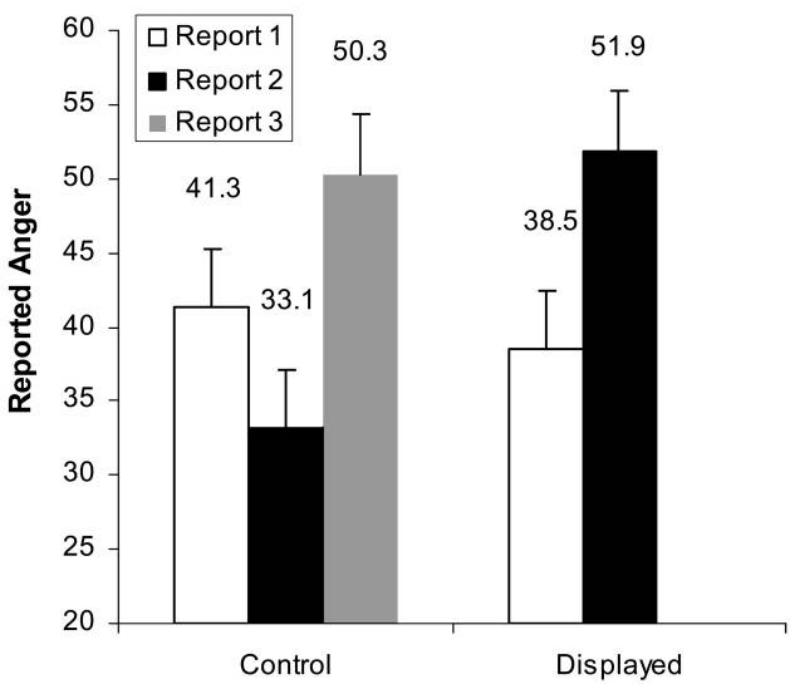

second or third report of anger, the majority of participants (78.3\% and $76.1 \%$, respectively) acknowledged that they had strategically displayed their emotions in an attempt to prevent unfair offers from their matched proposers. These numbers were significantly greater than chance $(z=3.83$, $p<.001$, and $z=3.54, p<.001$, respectively), and they did not differ from one another $(z=.25, p>.10)$. A sample of the comments suggested how comfortable participants were at gaming emotions and acknowledging it: (1) "I'm not as angry as I said. I just want him/her to give me more money." (2) "I did revise my anger level by increasing it. I wanted to push the proposer into making an allocation that would be fair to me." (3) "I decided it was OK to lie and tell the other party I was angrier than I am to ensure that I get a more fair-sized slice of the money." (4) "I decided to dramatically increase the reported level of anger in hopes that this would suggest to the proposer that I was infuriated with the lack of power I had in the first situation [DG] and would be willing to reject the offer so that neither of us would get the money unless she offered a higher amount."

In a few rare occasions, receivers decided to deliberately decrease their level of anger in an attempt either to increase their financial payoff ("If I show that I'm less mad, I will get more money") or to be more revengeful ("By choosing a low level of anger my proposer will make a money division in his favor, which I can reject").

Did the Strategy Work? Proposers were informed that receivers had reported their anger either before or after knowing that their level of anger would be sent to their matched proposers. Within each of these scenarios, a Pearson correlation was conducted between receivers' displayed level of anger and the share of the pie offered to them by their matched proposers. When proposers knew that receivers reported their level of anger before knowing that this 
information would be sent to their matched proposers (i.e., receivers could not be gaming emotions), there was a significant positive correlation between these two variables $(r=.32, p<.05)$. In other words, similar to experiment 1 , angrier receivers were offered a larger share of the pie from their matched proposers. However, when proposers knew that receivers reported their level of anger after knowing that this information would be sent to their matched proposers (i.e., receivers could potentially be gaming emotions), there was no correlation between receivers' level of anger and the share of the pie offered to them by their matched proposers $(r=-.05, p>.10)$. In this case, contrary to experiment 1 , proposers disregarded their matched receivers' reported anger. Also, the difference between the two correlations was significant $(z=1.77, p<.05$, one-tailed test).

\section{Discussion}

Experiment 2 provides further evidence that people strategically game emotions. It replicates experiment 1 and further demonstrates that people seem quite comfortable with faking their own emotions for pure financial benefits. When receivers in the control condition were told that their second report of anger would be sent to proposers and were then given the opportunity to modify it, they did not hesitate to inflate their prior display of anger reported a few seconds before. Also, thought processes gathered after the last report of anger rule out the alternative hypothesis that receivers might indeed be feeling worse as soon as they are reminded of the source of anger (i.e., their matched proposers). The vast majority of receivers acknowledged that they were exaggerating their emotions and, consistent with our hypothesis, that they were doing so in an attempt to extract a larger share of the pie from their matched proposers. Finally, while proposers represented the source of receivers' anger, the impact of receivers' emotions on proposers' decisions was contingent on the perceived credibility of the affective information. When proposers believed that the receivers' report of anger was credible, they offered a higher share to angrier receivers. However, when proposers inferred that receivers could be strategically gaming emotions, the former ignored the latter's report of anger.

\section{GAMING EMOTIONS OR EXPECTATIONS?}

Displays of emotions provide social cues (Keltner and Kring 1998; Morris and Keltner 2000; Thompson et al. 1999). To be precise, they help people to convey information about themselves to others. A sad face might convey empathy, while a happy expression might communicate confidence. As Deighton and Hoch (1993) have pointed out, emotion is a "communicative act, and audiences are able to interpret the intentions and meanings of emotion displays" (261). Therefore, when an individual chooses to game an emotional state in a dyadic negotiation, she or he is trying to manipulate inferences others will make about her or his future behavior. Hence, to game emotion is to convey in- formation. What makes emotions so special is the fact that people might strategically display an emotional expression (a) because it is readily available and well learned and (b) because they might actually believe it to be more persuasive than a communication of nonemotional information.

Consumer researchers have long investigated how firms, through advertising, may strategically elaborate emotional appeals in order to improve attitudes toward their ad/brand. These researchers have stressed the importance of distinguishing between rational versus emotional appeals (Rothschild 1987), instrumental versus expressive messages (Holbrook and Hirschman 1982), or dramatic versus argumentative ads (Deighton et al. 1989). Moreover, there is evidence supporting the relative effectiveness of affect-laden messages. For instance, in a study where 1,215 consumers rated 40 commercials on a dramatization scale, Deighton and colleagues (1989) showed not only the existence of drama-type versus argument-type ads but also a greater effectiveness of the former. Pham and colleagues (2001) have also demonstrated the superiority of emotion-based (vs. purely cognitive-based) judgment on the predictability of the number and valence of people's thoughts.

In our previous experiments, receivers did not have a choice between sending an emotional versus a nonemotional type of information to their matched proposers. It could be that receivers might not have been interested in conveying any emotional state per se but simply wanted to inform their matched proposers about their violated expectations. Since experiments 1 and 2 restricted receivers to send only their anger level, it was possible that they were simply trying to convey that the previous offer (in the DG) had been below their expectation and that they expected a larger offer in the UG.

In experiment 3 , receivers are presented with two measures after the DG: an expectation scale (e.g., "The previous offer was X below my expectations") and an anger scale (e.g., "The previous offer made me feel $\underline{X}$ angry"). During the targeted social interaction in the UG, receivers are given a choice between sending either their gamed expectation level or their gamed anger level to the matched proposer. Moreover, in an open-ended question, receivers are asked to justify their choice. This procedure allows us to assess whether receivers perceive both options as relatively different from one another (choice measure) and whether systematic and unique inferences are drawn (open-ended question). Also, proposers are asked right after seeing the reported level of expectation or anger to indicate the extent to which their matched receiver is an impulsive, irrational, and vindictive person. Proposers then make a choice on the division of the pie. We assess whether proposers' inferences about receivers' traits mediate the impact of receivers' reported information on proposers' division of the pie. Most important, we test whether there is a difference in the mediational analyses between expectation and anger information.

We hypothesize that (1) receivers will not perceive anger as simply another way of conveying information about one's 
violated expectations (their choice and justification should confirm it) and that (2) proposers will be more responsive to information about one's anger at a previous offer than to information about one's violated expectations on a previous offer (the mediational analyses should confirm it).

\section{EXPERIMENT 3}

\section{Method}

Participants and Procedure. One hundred and thirty students from the University of California, Berkeley, participated in this experiment. The procedure was similar to the one used in experiment 1 except for the following changes. First, receivers were asked to report their level of expectations and anger after their matched proposers' offer in the DG. To be precise, they were asked to indicate on a 101-point scale the extent to which this offer $(a)$ was above/below their expectations $(0=$ quite above my expectations; $50=$ met my expectations; 100 = quite below my expectations; any number from 0 to 100 is allowed) and (b) made them feel angry $(0=$ not angry at all; $50=$ mildly angry; $100=$ very angry; any number from 0 to 100 is allowed). Right before the targeted social interaction, all receivers were informed that they could send their matched proposers either their level of expectation or their level of anger. Whatever option was chosen, receivers could also update the level (i.e., to game it) before sending it off to their matched proposers. Receivers were also informed that their matched proposers would not know that they (receivers) had a choice of which piece of information to send nor would their matched proposers know that they were allowed to change their level of anger or expectation. Receivers then chose one of the pieces of information and were allowed to revise their report. After that, they were asked, in an open-ended question, to justify their choices.

The chosen number and type of information were indeed sent to the respective matched proposers. Proposers were then asked to indicate on a 9-point scale (9 = agree completely) the extent to which they agreed with the following statements: "I think my partner is an impulsive person"; "I think my partner can behave irrationally"; "I think my partner is a vindictive person." Finally, proposers made their decision on the division of the $\$ 10.00$, which was either accepted or rejected by their matched receivers.

\section{Results}

Manipulation Check. Not surprisingly, the majority (91\%) of the proposers chose the option that gave them a larger share of the pie. All subsequent analyses are conducted within this group ( $n=118 ; 59$ proposers/receivers). Proposers in the DG were given the option to choose either between P:\$7.00/R:\$3.00 versus P:\$3.00/R:\$7.00 or between $\mathrm{P}: \$ 7.50 / \mathrm{R}: \$ 2.50$ versus $\mathrm{P}: \$ 2.50 / \mathrm{R}: \$ 7.50$. The size of the offer (\$3.00 vs. \$2.50) did not influence participants' willingness to game expectations $\left(F(1,21)=0.24, p>.10, \eta_{p}^{2}=.01\right)$ or anger $\left(F(1,34)=.76, p>.10, \eta_{p}^{2}=.02\right)$. Nor did it in- fluence participants' preference on which information to send to their matched proposers $\left(\chi^{2}=.40, p>.10\right)$. The levels of this factor were then collapsed.

Gaming Option. Receivers were more likely to send the anger level $(61 \%)$ than the expectation level to their matched proposers $(z=1.69, p<.05$, one-tailed test). A chi-squared analysis showed that there were no gender effects $\left(\chi^{2}=.28, p>.10\right)$.

A possible explanation for participants' preference for anger over expectation was that receivers anticipated that the former would be psychologically easier to game. For example, emotions tend to vary more quickly than expectations. Thus a change in level of anger could be perceived as easier to justify to oneself than a change in expectations. If this were true, it could explain why receivers were more likely to choose the anger option in the first place. However, an analysis of variance with repeated measures reveals that this is not the case. The results show no interaction between timing of report (report 1 vs. report 2) and option (anger vs. expectation; $F(1,57)=2.07, p>.10$, $\left.\eta_{p}^{2}=.03\right)$. Those who chose to send the anger level inflated it as much $\left(M_{\text {report1 }}=47.6, \mathrm{SE}=4.5\right.$ vs. $M_{\text {report2 }}=75.8$, $\left.\mathrm{SE}=4.1 ; F(1,57)=36.1, p<.001, \eta_{p}^{2}=.39\right)$ as those who chose the expectation $\left(M_{\text {report1 }}=54.1, \mathrm{SE}=5.6 \mathrm{vs}\right.$. $M_{\text {report } 2}=71.6, \mathrm{SE}=5.1 ; F(1,57)=8.7, p<.005, \eta_{p}^{2}=$ $.13)$.

Thought Processes. To directly assess the reason behind receivers' behavior, a subsequent open-ended question asked receivers to justify their choice. Two coders, blinded to the purpose of the experiment as well as to the receivers' choice, categorized the answers into the following categories: $0=$ "Both options are similar. I'm somewhat indifferent between them." 1 = "Anger is more effective because it sends unique signals." $2=$ "Anger is less effective because it might backfire or because it is too hostile." $3=$ "Expectation is more effective because it is more precise and informative." $4=$ "Expectation is less effective because it is more confusing." $5=$ "Did not answer/Other." Category 0 would mean that anger is simply another way of reporting one's expectations, whereas categories 1-4 indicate that participants do perceive differences between the two options and choose the one they think will maximize their chances of getting a better offer from their matched proposers.

Twelve percent of participants were in category 5. Most important, only $3.4 \%$ of receivers reported indifference between the two options (category 0 ). Within the remaining participants $(n=50)$, the justifications varied as a function of choice. Among those who chose anger, 93.5\% did so because they believed it to be a stronger, more threatening, and vindictive signal (category 1): (a) "I think anger is a stronger force to push the proposer to raise the offer. Expectation sounds weaker than anger." $(b)$ "I chose to send the anger to scare my proposer and to make him/her think that I wouldn't be accepting an offer that didn't favor me as well." $(c)$ "Hopefully the proposer will be more inspired 
to share because of fear of "revenge." $(d)$ "Anger reflects desire for revenge." Among those who chose expectations, an interesting pattern emerged. Sixty percent chose it because they believed it to be a more effective, precise, and informative piece of information (category 3): (a) "I think the expectation will give the proposer a clearer idea about what I am looking for than any measure of anger would." (b) "I chose to send the expectation because I thought it would influence the proposer to share equally the $\$ 10.00$. If the proposer knows what I expect, then perhaps they will be more willing to cooperate." The remaining $40 \%$ chose it because they believed that the anger choice could actually backfire (category 2): (a) "This statement [expectations] was more neutral, not infused with feelings. Conveying a message of anger may work against me by making the proposer defensive and wanting to give less." (b) "The anger statement is too harsh to be sent. I didn't think they [the proposer] would have appreciated it much." (c) "Positive feedback almost always leads to a better chance of success. If he knows I'm angry, he might just offend me again."

It is therefore clear from the previous analysis that anger and expectations are perceived as distinctive pieces of information. Anger is considered to be stronger and more threatening than expectations.

Which Strategy Worked Best? A Pearson correlation was conducted between receivers' gamed level of anger (vs. expectation) and the share of the pie offered to them by their matched proposers. If anger represents a stronger and more effective signal (as most receivers hoped it would), a stronger correlation would emerge when proposers are presented with receivers' anger (vs. expectation) level. In fact, when receivers' reactions to the offer in the DG were presented to proposers in the anger format, proposers offered a larger share of the pie as the level of anger increased $(r=.44, p<.01)$, replicating the findings of previous experiments. When receivers' reaction to the offer in the DG was presented to proposers in an expectation format, the correlation disappeared $(r=-.20, p=.35)$. The difference between the two correlations was significant $(z=$ $2.38, p<.01$, one-tailed test).

Mediational Analysis. Recall that, before proposers decided on the offer, we asked them to indicate the extent to which the matched receiver was perceived as an impulsive, irrational, and vindictive person. The three items were strongly correlated $(\alpha=.81)$ and were then collapsed to form a single emotional trait index. We assessed whether the proposers' perceptions of their matched receivers as being an emotional individual would mediate the impact of the receivers' anger on their proposers' offer. That is, would proposers perceive angrier receivers as more impulsive, irrational, and/or vindictive, which, in turn, would lead proposers to offer their matched receivers a larger share of the pie?

Figure 4 summarizes the mediational analysis. As can be seen from part $A$ of figure 4, receivers who reported higher levels of anger were perceived as more impulsive, irrational, and/or vindictive by their matched proposers $(r=.68$, $p<.001)$. Similarly, receivers who were higher on this emotional trait got a larger share of the $\$ 10.00(r=.53, p=$ $.001)$. A Sobel test confirmed that the impact of reported anger on proposers' division of the $\$ 10.00$ was mediated by proposers' inferences about the receivers' emotional trait $(z=1.99, p<.05)$. Part B of figure 4 performs that same type of analyses for those who chose to send the expectation information. There was a marginal correlation between expectation and the emotional trait index $(r=.35, p=.10)$ and no correlation between the emotional index and receivers' share of the pie $(r=-.31, p>.10)$. The Sobel test was also nonsignificant $(z=-0.99, p>.10)$.

\section{Discussion}

Experiment 3 provides further evidence that people game emotions. Moreover, it shows that people intuit that anger does not equate expectation. Within the proposed paradigm, receivers anticipated that anger (vs. expectation) would be more effective and, hence, preferred to display it to their matched proposers. Moreover, their intuition seemed to be accurate. Those who chose to display a gamed level of anger were more likely to influence their partner's behavior than those who chose to display a gamed level of expectation. The reason for such effectiveness was due in part to the fact that anger leads to inferences about one's willingness to overreact-be impulsive, irrational, and vindictive-and, thus, to reject a given offer. The mediational analyses confirmed that such inferences mediated the impact of receivers' expressed anger on proposers' offer. Information about one's violated expectations had no such impact.

\section{GENERAL DISCUSSION}

Individuals believe that their expressed emotions can influence others' decisions in a social interaction. As a result, individuals have an incentive to game emotions in an attempt to improve their well-being. In a series of three experiments, we show that people deliberately inflate anger when they believe that this strategy can be financially beneficial. To be precise, receivers choose to inflate their reported level anger in an ultimatum game in order to ensure that proposers do not make them an unfair offer. Moreover, they seem quite comfortable in doing so for purely financial reasons and are willing to acknowledge it when asked.

Since our procedure involves a real-time negotiation with actual financial consequences, it is possible to address whether one's attempt to inflate emotions increases the material well-being in a given social interaction. Our experiments demonstrate that emotion gaming may well pay off. Proposers offered more money to receivers who expressed angrier feelings. However, the strategy worked only if proposers believed that receivers' reported emotions were credible. When proposers knew that receivers could be gaming emotions, receivers' strategy to inflate anger did not pay off, even in a scenario where proposers were the main source of receivers' mild anger (experiment 2). Finally, anger is 
FIGURE 4

MEDIATIONAL ANALYSES (EXPERIMENT 3)

$\underline{\mathrm{A}}$

Proposer's Perception of Receiver

(Impulsive/Irrational/Vindictive)

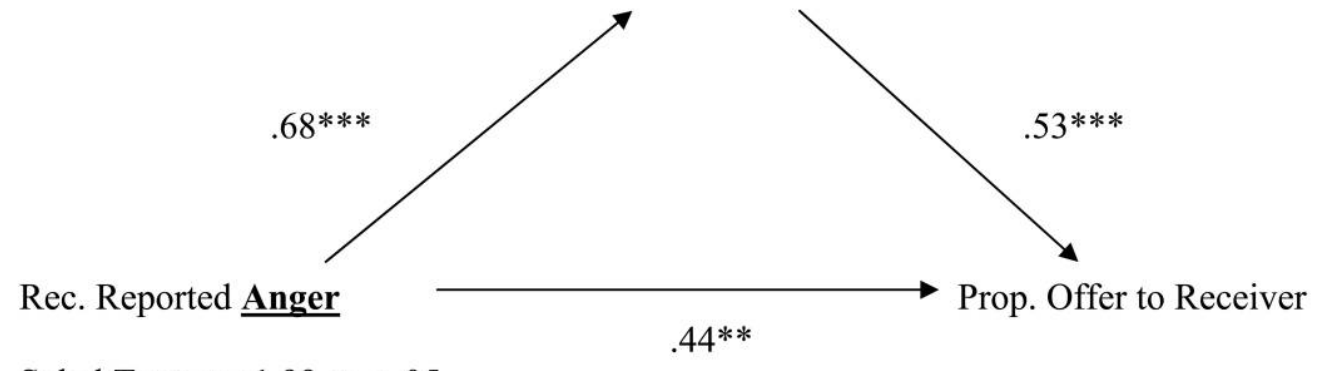

Sobel Test: $\mathrm{z}=1.99, \mathrm{p}<.05$

$\underline{B}$

\section{Proposer's Perception of Receiver}

(Impulsive/Irrational/Vindictive)
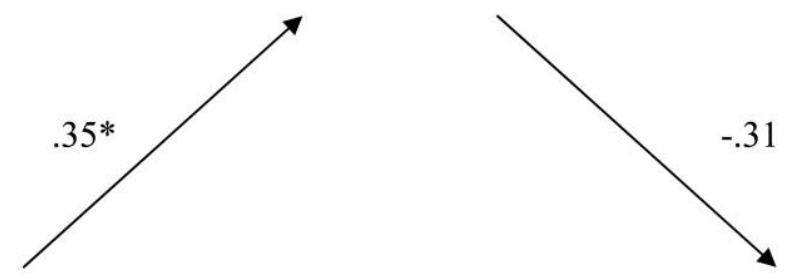

Rec. Reported Expectation

Sobel Test: $\mathrm{z}=-0.99, \mathrm{p}>.10$

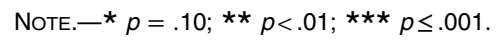

not simply a way of communicating to your interacting party that your expectation has been violated. Anger (vs. expectation) displays are perceived as stronger and more persuasive cues and tend to lead to inferences about revenge. Experiment 3 shows that receivers believed anger would be more effective than expectation (i.e., chose the former more often) and that proposers were indeed more responsive to it relative to information about violated expectations.

\section{The Costs and Willingness to Game Emotions}

Our experiments demonstrate that people are ready to acknowledge their strategic misrepresentation of emotional displays. However, there are potential psychological and physiological challenges associated with emotion gaming that may undermine this phenomenon. It is plausible that contextual cues can make moral costs (i.e., honesty concerns) higher or lower. A consumer may feel it is socially appropriate to fake anger to persuade the waiter to speed up service. However, a patient may feel that it is inappropriate to inflate the display of pain to get an earlier appointment when others with more serious symptoms would need to be put behind in the queue. As Mazar and colleagues (2008) have pointed out, the extent to which people can justify a dishonest behavior and consequently preserve a positive view of the self moderates people's willingness to game emotions. Finally, it is quite possible that there may be an asymmetry between situations where gaming emotions is designed to take advantage of others versus to avoid being taken advantage of. People may find it easier to justify the latter.

Physiological challenges can also play a major role. It is quite possible that people might not always be capable of physically expressing a faked emotional state. Professional poker players often hide their facial expression altogether with 
hats and sunglasses in part because of the difficulty associated with inhibiting facial expressions (Kappas, Bherer, and Thériault 2000). There is also a possibility of extrinsic costs. One may choose not to game emotions if she or he believes that there is a high chance of being caught. This is particularly true if one anticipates that the other can retaliate, which increases the costs of a nonsuccessful strategy. Future research could address the extent to which intrinsic (psychological and physiological) and extrinsic costs can influence people's willingness to game emotions.

\section{Faking: Intensity versus Type}

To fake an emotional state means to report a stronger or weaker than experienced affective state (i.e., misrepresent the intensity of the emotion) and/or to report a different affective state (i.e., misrepresent the type of emotion). As Ekman and Friesen (1975) have pointed out, there are several ways to express a nonexperienced emotion. Among them, people can (de)intensify emotions (i.e., to change the intensity) or mask emotions (i.e., to change the type). Our results focus on the former. It is possible that people might be more willing and/or capable of inflating a current state than expressing a different one. Second, a counterpart might be less capable of detecting the misrepresentation of an inflated (vs. different) emotional experience (see DePaulo et al. 2003). Therefore, it is an open question whether or not people would display a different emotional state when gaming emotions. Angry individuals might instead want to express sadness if they want to increase sympathy. Similarly, anxious speakers might smile not only to hide their anxiety but also to portray happiness. It would be interesting to investigate people's willingness and ability to fake a different type of emotion, as well as its impact on others' behavior.

\section{Lay Theories in Emotion Gaming}

Our findings show that emotion gamers in general are relatively good at predicting what others are likely to do once the latter are exposed to a given emotional expression. However, there are some circumstances in which the lay theories about others' reactions to one's expressed emotions might be inaccurate. Indeed, our third experiment hints to this inaccuracy because a meaningful fraction of participants wrongly predicted how others would react to their inflated level of anger. Specifically, $40 \%$ of receivers who choose to send expectation instead of anger information did so because they wrongly believed that expressing anger could backfire-that is, that proposers would have made worse offers to angrier receivers. Thus, it is worth investigating in which social contexts a lay theory mismatching is more or less likely to happen, as well as the consequences of such mismatching to both parties' well-being.

\section{Broadening the Scope}

The context of this research has been limited to a oneshot game in economics, which allows us to measure whether and how much people inflate anger in an attempt to improve their financial well-being. It is worth investigating if the effects hold when the number of interactions between matched-partners increases. For instance, a seller might learn the buyer's emotion gaming strategies and disregard the signal altogether over time. Similarly, the buyer anticipating this might have to invest in reputation building. Two outcomes could follow: the buyer could either $(a)$ avoid emotion gaming altogether (because she or he would be bluffing) or $(b)$ be prepared to reject an unfair offer after an anger inflation in order to build reputation.

Different social contexts and emotional states should also be explored. At the time the experiments were conducted for this article, the democratic primary in Iowa provided us with another example of how expressed emotions could have a powerful effect on others' impressions and decisions. Senator Hillary Clinton's unexpected tears during an interview became a media spotlight on whether or not she should have expressed or concealed her feelings. Under the title "Tears Have Turned Campaigns," the Wall Street Journal speculated on how emotional displays might have helped or hurt several candidates in the past (Chozick 2008). In summary, emotion gaming can occur in many different social settings and produce multiple outcomes. This provides an incredible array of opportunities to those interested in this line of research.

\section{REFERENCES}

Adelmann, Pamela K. and Robert B. Zajonc (1989), "Facial Efference and the Experience of Emotion," Annual Review of Psychology, 40 (January), 249-80.

Allred, Keith G. (1999), "Anger and Retaliation: Toward an Understanding of Impassioned Conflict in Organizations," in Research on Negotiation in Organizations, Vol. 7, ed. Robert J. Bies, Roy J. Lewicki, and Blair H. Sheppard, Stamford, CT: JAI, 27-58.

Allred, Keith G., John S. Mallozzi, Fusako Matsui, and Christopher Raia (1997), "The Influence of Anger and Compassion on Negotiation Performance," Organizational Behavior and Human Decision Processes, 70 (June), 175-87.

Andrade, Eduardo B. and Teck-Hua Ho (2007), "How Is the Boss's Mood Today? I Want a Raise," Psychological Science, 18 (August), 668-71.

Ashforth, Blake E. (1993), "Emotional Labor in Service Roles: The Influence of Identity," Academy of Management Review, 18 (January), 88-115.

Baron, Robert A. (1990), "Environmentally Induced Positive Affect: Its Impact on Self-Efficacy, Task Performance, Negotiation, and Conflict," Journal of Applied Social Psychology, 20 (March), 368-84.

Baron, Robert A., Suzanne P. Fortin, Richard L. Frei, Laurie A. Hauver, and Melissa L. Shack (1990), "Reducing Organizational Conflict: The Role of Socially-Induced Positive Affect," International Journal of Conflict Management, 1 (2), 133-52.

Barry, Bruce (1999), "The Tactical Use of Emotion in Negotiations," in Research on Negotiation in Organizations, Vol. 7, ed. Robert J. Bies, Roy J. Lewicki, and Blair H. Sheppard, Stamford, CT: JAI, 93-121. 
(2008), "Negotiator Affect: The State of the Art (and the Science)," Group Decision and Negotiation, 17 (January), 97-105.

Barry, Bruce and Richard L. Oliver (1996), "Affect in Dyadic Negotiations: A Model and Propositions," Organizational Behavior and Human Decision Processes, 67 (August), 127-43.

Baumeister, Roy F. (1982), "A Self-Presentational View of Social Phenomena," Psychological Bulletin, 91 (1), 3-26.

Berkowitz, Leonard (1987), "Mood, Self-Awareness, and Willingness to Help," Journal of Personality and Social Psychology, 52 (April), 721-29.

- (1989), "The Frustration-Aggression Hypothesis: An Examination and Reformulation," Psychological Bulletin, 106 (July), 59-73.

Boas, Maxell and Steve Chain (1976), Big Mac: The Unauthorized Story of McDonald's, New York: Dutton.

Buchan, Nancy R., Rachel T. A. Croson, and Eric J. Johnson (2004), "When Do Fair Beliefs Influence Bargaining Behavior? Experimental Bargaining in Japan and the United States," Journal of Consumer Research, 31 (June), 181-90.

Carnevale, Peter J. and Alice M. Isen (1986), "The Influence of Positive Affect and Visual Access on the Discovery of Integrative Solutions in Bilateral Negotiations," Organizational Behavior and Human Decision Processes, 37 (February), $1-13$.

Chozick, Amy (2008), "Tears Have Turned Campaigns," Wall Street Journal, January 8, A6.

Clark, Margaret S., Sherri P. Pataki, and Valerie H. Carver (1996), "Some Thoughts and Findings on the Self-Presentation of Emotions in Relationships," in Knowledge Structures in Close Relationships: A Social Psychological Approach, ed. Julie Fitness and Garth J. O. Fletcher, Mahwah, NJ: Erlbaum, 247-74.

Coté, Stéphane (2005), "A Social Interaction Model of the Effects of Emotion Regulation on Work Strain," Academy of Management Review, 30 (3), 509-30.

Davidson, Martin N. and Leonard Greenhalgh (1999), "The Role of Emotion in Negotiation: The Impact of Anger and Race," in Research on Negotiation in Organizations, Vol. 7, ed. Robert J. Bies, Roy J. Lewicki, and Blair H. Sheppard, Stamford, CT: JAI, 3-26.

Deighton, John A. and Stephen J. Hoch (1993), “Teaching Emotion with Drama Advertising," in Advertising Exposure, Memory and Choice, ed. Andrew A. Mitchell, Hillsdale, NJ: Erlbaum.

Deighton, John, Daniel Romer, and Josh McQueen (1989), "Using Drama to Persuade," Journal of Consumer Research, 16 (December), 335-43.

DePaulo, Bella M., James J. Lindsay, Brian E. Malone, Laura Muhlenbruck, Kelly Charlton, and Harris Cooper (2003), "Cues to Deception," Psychological Bulletin 129 (1), 74-112.

Dunn, Jennifer R. and Maurice E. Schweitzer (2005), "Feeling and Believing: The Influence of Emotion on Trust," Journal of Personality and Social Psychology, 88 (March), 736-48.

Ekman, Paul and Wallace V. Friesen (1975), Unmasking the Face: A Guide to Recognizing Emotions from Facial Clues, Englewood Cliffs, NJ: Prentice-Hall.

Forgas, Joseph P. (1998), "On Feeling Good and Getting Your Way: Mood Effects on Negotiator Cognition and Bargaining Strategies," Journal of Personality and Social Psychology, 76 (June), 565-77.

Goffman, Erving (1959), The Presentation of the Self in Everyday Life, Garden City, NY: Doubleday.

Gosserand, Robin H. and James M. Diefendorff (2005), "Emotional
Display Rules and Emotional Labor: The Moderating Role of Commitment," Journal of Applied Psychology, 90 (November), 1256-64.

Grandey, Alicia A. (2003), "When 'The Show Must Go On': Surface and Deep Acting as Determinants of Emotional Exhaustion and Peer-Rated Service Delivery," Academy of Management Journal, 46 (February), 86-96.

Gross, James J. and Robert W. Levenson (1997), "Hiding Feelings: The Acute Effects of Inhibiting Negative and Positive Emotion," Journal of Abnormal Psychology, 106 (February), 95-103.

Gueguen, Nicolas (2002), "The Effects of a Joke on Tipping when It Is Delivered at the Same Time as the Bill," Journal of Applied Social Psychology, 32 (September), 1955-63.

Hochschild, Arlie R. (1983), The Managed Heart: Commercialization of Human Feelings, Berkeley: University of California Press.

Holbrook, Morris B. and Elizabeth C. Hirschman (1982), "The Experiential Aspects of Consumption: Consumer Fantasies, Feelings, and Fun," Journal of Consumer Research, 9 (September), 132-40.

Jones, Edward E. and Thane S. Pittman (1982), "Toward a General Theory of Strategic Self-Presentation," in Psychological Perspectives on the Self, Vol. 1, ed. Jerry M. Suls, Hillsdale, NJ: Erlbaum, 231-62.

Kappas, Arvid, Francois Bherer, and Melanie N. Thériault (2000), "Inhibiting Facial Expressions: Limitations to the Voluntary Control of Facial Expressions of Emotion," Motivation and Emotion, 24 (December), 259-70.

Keltner, Dacher and Ann M. Kring (1998), "Emotion, Social Function, and Psychopathology," Review of General Psychology, 2 (September), 320-42.

Kopelman, Shirli, Ashleigh Rosette, and Leigh Thompson (2006), "The Three Faces of Eve: Strategic Displays of Positive, Negative, and Neutral Emotions in Negotiations," Organizational Behavior and Human Decision Processes, 99 (January), 81-101.

Mazar, Nina, On Amir, and Dan Ariely (2008), "The Dishonesty of Honest People: A Self-Concept Maintenance Theory," Journal of Marketing Research, 45 (6), 633-44.

Morris, J. Andrew and Daniel C. Feldman (1996), "The Dimensions, Antecedents, and Consequences of Emotional Labor," Academy of Management Review, 21 (October), 986-1010.

Morris, Michael W. and Dacher Keltner (2000), "How Emotions Work: The Social Function of Emotional Expression in Organizations," in Research in Organizational Behavior, Vol. 22, ed. Barry M. Staw and Robert I. Sutton, New York: Elsevier, 1-50.

Pataki, Sherri and Margaret S. Clark (2004), "Self-Presentations of Happiness: Sincere, Polite, or Cautious?" Personality and Social Psychology Bulletin, 30 (7), 905-14.

Pham, Michel T., Joel B. Cohen, John Pracejus, and G. David Hughes (2001), "Affect-Monitoring and the Primacy of Feelings in Judgment," Journal of Consumer Research, 28 (September), 167-88.

Pillutla, Madan and J. Keith Murnighan (1996), "Unfairness, Anger, and Spite: Emotional Rejections of Ultimatum Offers," Organizational Behavior and Human Decision Processes, 68 (December), 208-24.

Rafaeli, Anat and Robert I. Sutton (1987), "Expression of Emotion as Part of the Work Role," Academy of Management Review, 12 (January), 23-37. 
Rothschild, Michael L. (1987), Marketing Communications, Lexington, MA: Heath.

Sanfey, Alan G., James K. Rilling, Jessica A. Aronson, Leigh E. Nystrom, and Jonathan D. Cohen (2003), "The Neural Basis of Economic Decision Making in the Ultimatum Game," Science, 300, June 13, 1755-57.

Schlenker, Barry R. and Beth A. Pontari (2000), "The Strategic Control of Information: Impression Management and SelfPresentation in Daily Life," in Psychological Perspectives on Self and Identity, ed. Abraham Tesser, Richard B. Felson, and Jerry M. Suls, Washington, DC: American Psychological Association, 199-232.

Sinaceur, Marwan and Larissa Z. Tiedens (2006), "Get Mad and More than Even: When and Why Anger Expression Is Effective in Negotiations," Journal of Experimental Social Psychology, 42 (May), 314-22.

Spiro, Rosann L. (1983), "Persuasion in Family Decision Making," Journal of Consumer Research, 9 (March), 393-402.

Thompson, Leigh L., Janice Nadler, and Peter H. Kim (1999), "Some Like It Hot: The Case for the Emotional Negotiator," in Shared Cognition in Organizations: The Management of Knowledge, ed. Leigh L. Thompson, John M. Levine, and David M. Messick, Mahwah, NJ: Erlbaum, 139-62.
Tidd, Katti L. and Joan S. Lockard (1978), "Monetary Significance of the Affiliate Smile," Bulletin of the Psychonomic Society, 11 (June), 344-46.

Travis, Carol (1989), Anger: The Misunderstood Emotion, New York: Touchstone.

van Kleef, Gerben A., Carsten K. de Dreu, and Antony S. R. Manstead (2004), "The Interpersonal Effects of Anger and Happiness in Negotiations," Journal of Personality and Social Psychology, 86 (January), 57-76.

(2006), "Supplication and Appeasement in Conflict and Negotiation: The Interpersonal Effects of Disappointment, Worry, Guilt, and Regret," Journal of Personality and Social Psychology, 91 (July), 124-42.

Vohs, Kathleen D., Roy F. Baumeister, and Natalie J. Ciarocco (2005), "Self-Regulation and Self-Presentation: Regulatory Resource Depletion Impairs Impression Management and Effortful Self-Presentation Depletes Regulatory Resources," Journal of Personality and Social Psychology, 88 (April), 632-57.

Zeman, Janice and Judy Garber (1996), "Display Rules for Anger, Sadness, and Pain: It Depends on Who Is Watching," Child Development, 67 (June), 957-73. 